\title{
Some insights of novel COVID 19 virus: structure, pathogenicity and immunity aspects
}

\author{
A.M. Al-AAlim ${ }^{1}$, M.A. Hamad ${ }^{2 *}$ and A.A. AL-ledani ${ }^{3}$ \\ ${ }^{1,2}$ Department of Microbiology, College of Veterinary Medicine, University of Mosul, Mosul, ${ }^{3}$ Department of Microbiology, \\ College of Veterinary Medicine, University of Basrah, Basrah, Iraq, *Corresponding author \\ Email: ${ }^{1}$ ammarmahmmod@uomosul.edu.iq, ${ }^{2}$ mahmah1073@uomosul.edu.iq, ${ }^{3}$ aliedany65@ yahoo.com
}

(Received April 10, 2020; Accepted April 24, 2020; Available online June 13, 2020)

\begin{abstract}
COVID- 19 is a highly infectious disease where the first infected case reported in Wuhan city-China, then it was spread worldwide. The causative agent belongs to novel enveloped single linear positive-sense stranded RNA Coronavirus, which is also called SARS-CoV-2 and has an affinity to lung cells. The genetic analysis of SARS-CoV-2 suggested that this novel strain may be developed from the animal. origin by recombination between a bat SARS-like CoV and a coronavirus of unknown origin. The ability of the rapid spread of the SARS-CoV-2 virus from person to other is similar or even more than to other human viruses like influenza or plague leading to be announced as a pandemic by WHO in 2020. The mortality rate in SARS-CoV-2 increased day by day and this led the scientists to search for ways to control the virus. Most of the deaths in aged patients may be due to immune response complications where $70 \%$ of patients showed lymphopenia. This review provided some details about structure, pathogenicity, and immune response against SARS-CoV-2. The facts in this review lead to suggest that in most cases the death in SARS-CoV-2 may occur via loss of systemic inflammatory response control which leading to lung injury followed by pneumonia, acute respiratory distress syndrome (ARDS), and respiratory failure, hence the death especially in old patients. In concluding the early effective control of both innate and adaptive immunity may be a critical key factor in protection against SARS-CoV-2.
\end{abstract}

Keywords: SARS-CoV-2, ARDS, Coronavirus, MERS-CoV

DOI: 10.33899/ijvs.2020.126898.1408, ( 2020, College of Veterinary Medicine, University of Mosul.

This is an open access article under the CC BY 4.0 license (http://creativecommons.org/licenses/by/4.0/).

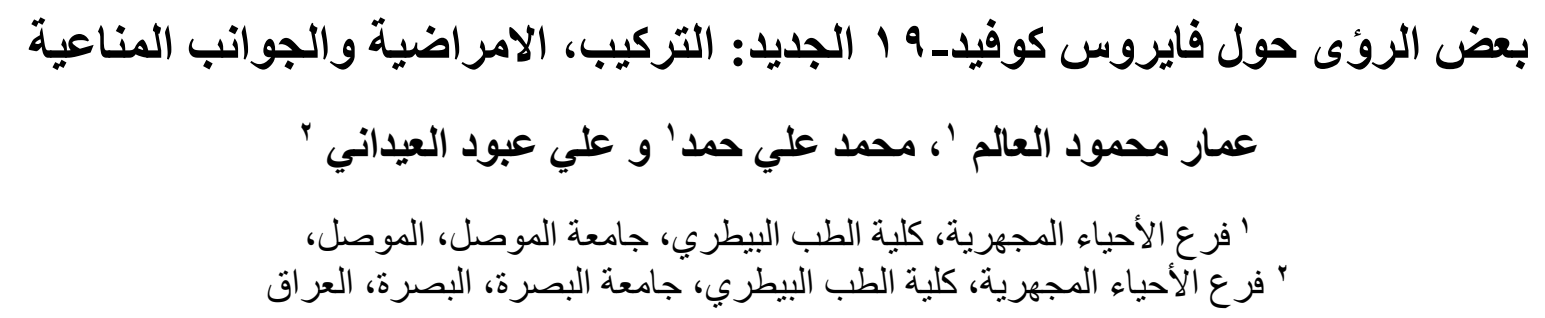

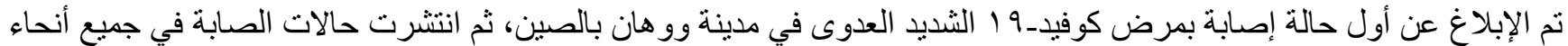

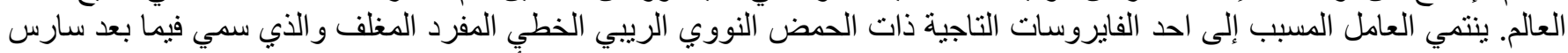

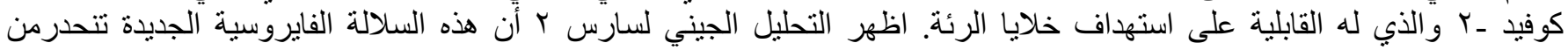

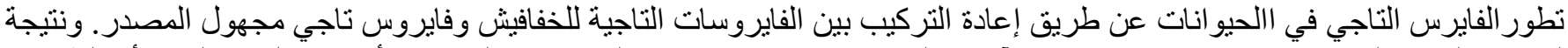

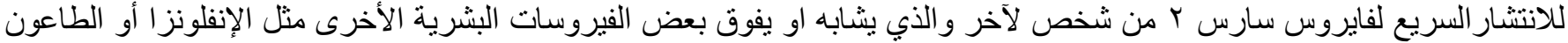

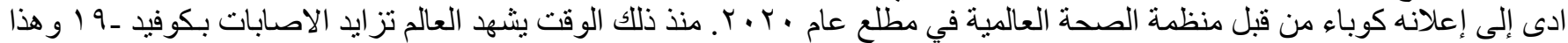




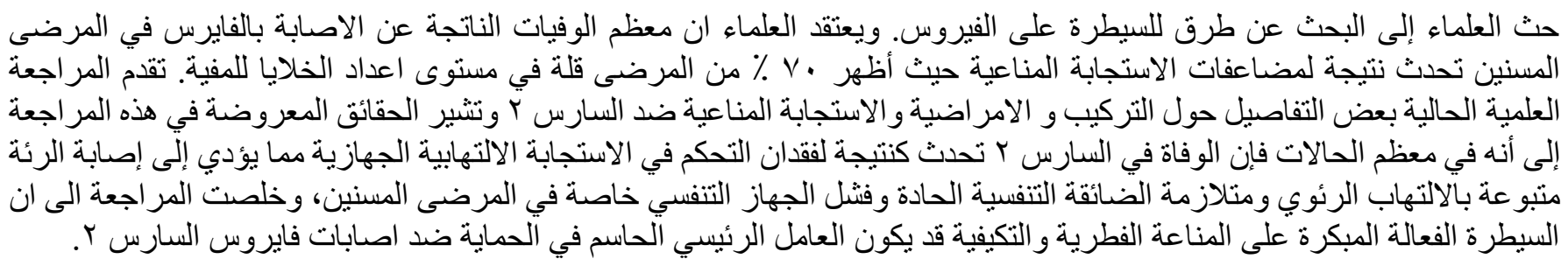

\section{Introduction}

On 11 March 2020 the WHO declared that SARS -CoV2 is pandemic after increased the number of cases in all countries, reaching 118,000 cases with about 4,300 deaths in 114 countries infected. From this declaration, the cases increased dramatically reaching 2,078,605 infected cases and 139,515 deaths in 213 countries (1). COVID -19 was first diagnosed in our country (Iraq) in Najaf city on 24February, then cases increased to 1,415 infections with 79 deaths and 812 recovered cases until the last update of Iraqi health ministry (2). The source of the outbreak was from China, in which the first report of the infection in late 2019 when reported unknown cause of cluster pneumonic cases in Wuhan, Hubei. Later in 7/1/2020, a novel coronavirus (SARS-CoV-2) was isolated and confirmed as the cause of pneumonia (3) and later on WHO named the disease caused by SARS-CoV-2 as Coronavirus Disease-19 "COVID-19" (4). As COVID-19 is a new emergency concern virus, our responsibility as scientists and researchers is to understand the viral zoonoses in wild or pet animals and their effects on the population's health, so this article draws attention to some insights of structure and immunological aspects of COVID19.

\section{Coronavirus: structure and replication}

Coronavirus belongs to the family Coronaviridae in Subfamily Orthocoronavirina. And the later has four genera; consist of alphacoronavirus, betacoronavirus, gammacoronavirus, and delta coronavirus containing several viruses that infect animals and humans. These viruses can be clustered according to their serological. and genetic properties into three main groups. Then the first two groups are subdivided into ( $\mathrm{a}$ and $\mathrm{b}$ ) as following: Group 1a includes viruses causing disease in swine, canine and feline, while group $1 \mathrm{~b}$ contains human coronaviruses and bat coronaviruses. Group 2a and b include viruses that affect mice, rats, bovine, porcine, canine, cat, raccoon, civet, bat, and human SARS coronavirus. Group 3 contains avian coronavirus. All these viruses can cause pneumonia, gastrointestinal. infection, polyserositis, sialodacryoadenitis, hepatitis, encephalomyelitis, and nephritis that producing severe economic losses in animals and birds. Farther than human coronaviruses are known to cause common cold like diseases (5-8). There are three strains adopted for human infection inclusive human CoV-OC43, HCoV-229E and HCoV-OC43 (8), but in last 20 years, human serious outbreaks have emerged in 2003 from coronavirus included severe acute respiratory syndrome coronavirus SARS-CoV (9), and Middle East respiratory syndrome coronavirus MERS-CoV (10) and give this virus special importance as they jumped species barrier (11).

All coronaviruses share the same structure which is spherical. (80-220 nm) envelope decorated with $20 \mathrm{~nm}$ long club-shaped large spikes enclosing icosahedral contain helical nucleocapsid, which composed of 26 to 32 kilobases linear single-stranded RNA positive-sense making them the largest non-segmented RNA virus. The envelope of coronaviruses contains $\mathrm{S}, \mathrm{M}$, and $\mathrm{E}$ proteins in addition to core $\mathrm{N}$ protein which attached to viral RNA allowing the package of the genome into nucleocapsid. The $\mathrm{S}$ homotrimeric spikes protein is a heavily glycosylated protein required for entry of the virus into host cells. Viral S spike found in two subunits $S 1$ and $S 2$ as a result of $S$ protein cleavage by host furin-like proteases during replication. Both $\mathrm{M}$ and $\mathrm{E}$ proteins are responsible for virus shape, and the role of $\mathrm{E}$ protein in orchestrating assembly of mature viral envelope. Also, E protein help in viral release from cells. Some betacoronaviruses have hemagglutination spike on their surfaces. Infectious RNA encoded both structural and nonstructural proteins within the $3^{\prime}$ and $5^{\prime}$ ends as well as RNA-dependent RNA polymerase (RdRP) in addition to important nonstructural proteins of the virus $(5,8)$.

After virus entry, the viral RNA translation begins from the $5^{\prime}$ end to produce the RdRP, which is an enzyme utilized viral RNA as a template to produce subgenomic mRNAs from intermediates subgenomic negative strands. The viral protein then synthesized by translating subgenomic mRNAs associated with the production of genomic viral RNA followed by an assembly of virions from viral genomic with structural proteins and budding using smooth endoplasmic reticulum Golgi intermediate compartment pathway $(5,8)$.

\section{Some aspects of COVID-19 Virus pathogenicity}

SARS-CoV-2 is a new strain so all ages (newborn to old) are susceptible to infection. SARS-CoV-2 has killed people more than closely related viruses SARS-CoV and MERS$\mathrm{CoV}$ virus together (4), which reach $6.7 \%$ (case fatality) in 
last known cases. The main weapon of the virus is its ability to spread from person to person (12). The main route of transmission is the inhalation of a droplet containing the virus following coughing, sneezing of the sick person also close contact with any contaminated surfaces from an infected person, this allows the virus to reach the lung via nose or mouth $(12,13)$. Researches revealed that SARSCoV-2 may remain in the air at least for hours (14). Also, the SARS-CoV-2 virus was detected in the feces of infected persons, so the fecal-oral route may also be considered $(13,15)$. According to Lu et al. (16), the ocular route should not be ignored, saliva, also pays attention to the dentist as a source of infection (17). The asymptomatic carriers facilitate the spread of infection between individuals (18), similar reports came from Germany showed that the virus clustered in family, who returned from Wuhan with asymptomatic young boy positive to SARS-COV-2 (19).

The rapid spreading of the virus indicates that mutation occurs in its nucleic acid, which facilitates faster spread. Mutation in RNA viruses occurs in six magnitude rates leading to 2-3 novel viruses every year (20). Homologous or heterologous "non-coronaviral" RNA recombination may occur and result in new serotypes or biotypes or acquired novel genes, for example, SARS-CoV has appeared through recombination of bats SARS-related coronaviruses (SARSr$\mathrm{CoVs}$ ). In the case of SARS-CoV-2 epidemiological investigations suggested that the first patient was gained the virus from wild animals at the Huanan seafood wholesale market /China, where different species of wild and domestic animals are sold in these traditional. places included dead and live animals, blood, and body fluids of an animal that act as a source for infectious diseases and aid to produce virus jump species barriers (11).

The genetic studies revealed that COVID-19 is genetically $79 \%, 50 \%$, and $88 \%$ close symmetry to SARS$\mathrm{CoV}$, MERS-CoV and two bat SARSr-CoV respectively $(8,21)$, this led to propose that SARS-CoV-2 may be originated from recombination between a bat SARS-like $\mathrm{CoV}$ and a coronavirus of unknown origin (11), but some researchers believed that pangolins were SARS $\mathrm{CoV} 2$ intermediate host $(22,23)$ in which mutations and natural. selection caused acceptation of the new receptor-binding domain (RBD) functional. site (24). This mutation made COVID-19 $\mathrm{S}$ protein to has a higher attraction to angiotensin-converting enzyme 2 ACE2 similar to SARS$\mathrm{CoV}(8)$. The spike $\mathrm{S}$ protein recognizes the receptors on the cell surface of mammals (11). The $\mathrm{S}$ spike protein of COVID-19 has a further furin-analogous protease cleavage location (RRAR $\downarrow S V$ ) which is N-terminus into the S1/S2 location (AYT $\downarrow M$ ) while it is missing in SARS-Co with else furin-like protease fission $\mathrm{S}^{\prime}$ location (KR $\downarrow S F$ ) which is conforming to that in SARS-CoV (25). Also, according to another study, various SARS-CoV RBD-specific monoclonal. antibodies do not link to SARS-CoV-2 S protein (26).

The present question, why SARS-CoV-2 killed people more than SARS-CoV? This may be partly because SARS$\mathrm{CoV}-2$ was spread more rapidly than SARS-CoV as well as the asymptomatic spreader of virus especially children and teenagers $(19,27)$. Genomic analysis of SARS-CoV-2 from infected persons showed difference by less than 0.1 percent which may indicate that the virus detected rapidly after its emergence (21). Genetic analyses of ARS-CoV-2 genomes show two major types $\mathrm{L}$ and $\mathrm{S}$, the $\mathrm{L}$ type is more prevalent than the $\mathrm{S}$ type, although $\mathrm{L}$ type decreased by Human intervention that put severe selective pressure on the L type, which possibly aggressive and more quickly spread, instead to evolutionarily older less aggressive $\mathrm{S}$ type which may continuously spread to more individuals under weaker selective pressure (24), as the virus was continuous spreading excessive mutations might emerge which may construct a highly virulent virus, so the monitoring ought to be indispensable (8).

\section{Immunological. aspects in SARS-CoV-2}

As a novel virus, protective immunity was not developed against it yet (4). The virus has a similar genome to SARS$\mathrm{CoV}$ and this must take in mind when discussing immunological. aspects as both viruses have the same receptor binding domain (RBD) site as angiotensinconverting enzyme 2 and have a long incubation period of about 14 days (28).

The infected person shows cytokine storm which is characterized with a high level of cytokines G-CSF, MIP1A, MCP-1, IP-10, IL-2, IL-7, IL-10, and TNF $\alpha$ mediated the pro-inflammatory especially in advance cases associated with lymphopenia and pneumonia (29), this leads to injury of the lung as a response to the inflammatory process and causes acute pneumonitis, respiratory failure, shock and death due to multiple organ failure (28). Innate immunity was important in the early response to viral infection and regulation of cellular immunity to viral infection. The innate immunity depends on the recognition of molecules called pathogen-associated molecular patterns (PAMPs) in virus by its pattern resonation receptors PRRs called Toll-like receptor (TLR) found in a variety of cells including lung cell (30). TLR especially TLR3 is specific for double-strand RNA and TLR7, TLR8 for single-strand RNA found in the endosome. Cytoplasm receptor as melanoma discriminationassociation gene 5 (MDA5) and retinoic-acid-inducible gene RIG-I could be activated downstream signaling either by Myeloid differentiation primary response 88 or through mitochondrial. antiviral. signaling protein. All pathways lead to the production of interferon type 1 and inflammatory interleukin 1 and 12 and tumor necrosis factor TNF which was important to induce antiviral effect $(6,7,31)$. The most 
important factor in innate immunity is interferon production because it affects different cells after producing endocrinal, exocrinal, or autocrinal effect by binding to interferon receptor (IFNAR) on the cell surface and activation Janus kinase JAK/ signal transduction and activator transcription STAT pathway and tyrosine Kinase TYK2 that phosphorylate STAT and causes its complex formation with IFN regulatory factor 9 (IRF9) results in activation of IFN stimulated response gene and up-regulation control expression of interleukin stimulation gene and releases of IFN-1 which prevents viral. maturation and replication and mediated of degraded RNA of the virus. This was enough to stop virus dissemination in the early stage of the disease $(6,7,28,31)$. Interferons have a crucial role in defense against coronavirus diseases. The IFN production could be suppressed by coronaviruses either by stopping signaling through STATS1 phosphorylation decreases or by evasion via generation replicated double-membrane vesicles lack RPPs or destruction of cytoplasmic sensor causing dsRNA not discover by host or inhibition transcription factor IRF3. All these strategies were found in the SARS CoV and MERS $\mathrm{CoV}$ by its structural or nonstructural proteins and may be used by the novel COVID-19 virus (Figure 1) $(28,31)$. The suppression of innate immune responses by respiratory viruses is a strategy for efficient virus replication and initiation. In this situation host's immune response is incomplete, delayed or absent, a strong response (after the delay) may cause tissue damage, so down-regulation of IFN signaling provided sufficiently strong and prevent explosive innate immune responses and protect from the immunopathy (30). Also, the RPPS cannot produce signals unlit virus internalization in endosomes or after cells lysis and released viral component (5-7). The production IFN and chemotactic agent mediate immune responses against the virus can lead to regulate the depositions of leukocytes in the lungs, which leads to severe immune responses or immune insufficiency that allows the virus to increase its replication and cause tissue damages by chaining in chemotactic agent relapsed (32). In many cases of SARS-CoV 2 infection occurs firstly as an asymptomatic carrier and may cause dysregulation of IFN1 production and infiltration of neutrophils and monocytes into the lung and increase of this cell infiltration associated with proinflammatory cytokine influx as result from active SARS-CoV 2 replication, lately leading to losing control of innate immunity and produced massive destruction in lung tissue (28).

Most cases of death in SARS-CoV-2 were due to loss of systemic inflammatory response control as a result of the production of cytokine storm that manifested by proinflammatory cytokines and chemokines accumulation in large amounts which lead the body to be attacked by the immune system, hence leading to lung injury followed by pneumonitis and acute respiratory distress syndrome (ARDS) and respiratory failure, then death $(28,33)$. The fatality rates of young infected with SARS- CoV-2 infection were zero and can be explained by the distinct innate immune responses (IFN) in young than the old persons. In young, innate immune responses were strong and effective and may cause early interferon's production and associated with incomplete immune system development in the young. A critical. correlation between the innate immune response and the death rates in adults may explain by loss of control and increase interferon-mediated immune responses (34).

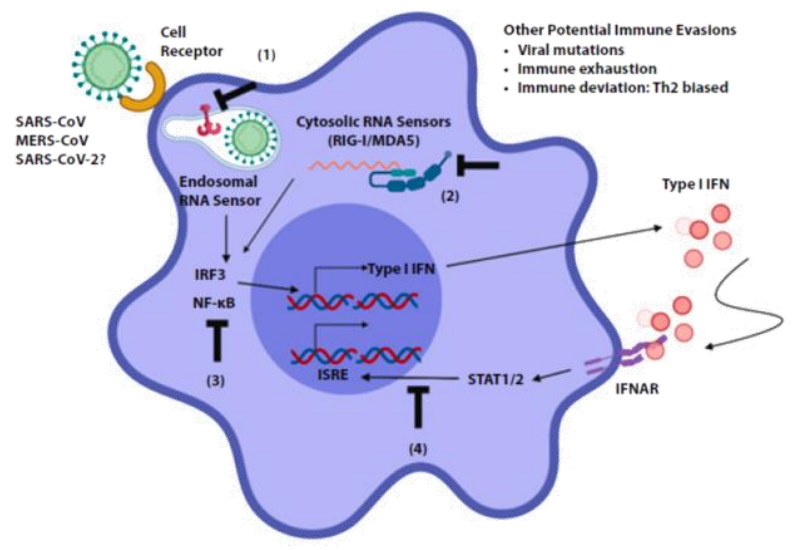

Figure 1: Possible immune escape mechanisms participate by SARS-CoV, MERS-CoV, and SARS-CoV-2. Coronaviruses overlap for numerous steps through primary innate immune response, inclusive RNA sensing $(1,2)$, signaling passageway of type I IFN output (3), STAT1/2 stimulation toward of IFN/IFNAR (4) as shown by oppressive marks, which belated or inhibit type I IFN responses that affect onto adaptive immune activation. protracted viral. continuance worsens inflammatory responses which might procure immune limpness and immune repression as a feedback regulatory mechanism. Biased Th2 type response also tends to poor consequences of the disease (28).

Bao et al. (35) suggested the patient that firstly infected with SARS-CoV-2 will not be infected again. This may be due to the development of solid immunity to virus infection. There is evidence that convalescence patients produce both specific humoral and cellular immune response after 2 weeks of recovery, and will show elevated $\mathrm{IgG}$ antibodies titers with an efficient cellular immunity although the cytotoxic $\mathrm{T}$ cells remained in low count numbers (36). In general, immune responses mediated by $\mathrm{T}$ cells is required to control of virus infection by the aid of antigen-presenting cells (APC) and cytokines, cytotoxic $\mathrm{T}$ cells kill cells infected virus and $\mathrm{T}$ helper cells regulated overall response also activation of B cells were important to produce antibodies against viral infection $(6,7,28)$. $70 \%$ of SARS-CoV-2 showed lymphopenia (15). Also, in severe cases, CD4+ and 
CD8+T lymphocytes were mainly decreased $(37,38)$. The CD4+, CD8+ T cells, and B cells are essential for viral clearance in different disease stages, and restoration of leuko-monocytes counts in peripheral blood provides a good prognosis for COVID-19 infection (39).

The innate immune responses are required to control the disease by producing IFN in the early stages of infection which provide communication between immune cells and produce natural killer (NK) cells and stimulation of macrophages; so, interferon provides crucial role against coronavirus infection (34). Lymphocyte sequestration during viral infection is responsible for peripheral blood lymphocytopenia and increased number in the last stage comes from moving of lymphocyte between tissues or organs and peripheral blood $(40,41)$. It was hypothesized that the SARS-CoV-2 virus passes mucous membranes and enters the lungs via the respiratory tract and causes viremia when spreading from lung to peripheral blood and attack the lungs, heart, kidney, and gastrointestinal tract, which express Angiotensin-converting enzyme 2 (ACE2). After 8 days the symptoms of Acute respiratory distress syndrome (ARDS) will appear $(40,42)$.

The attack of the virus causes severe illness in the patient during 7 to 14 days post-infection, in the early stage of the disease the peripheral white blood cells count was not affected strongly followed by lymphopenia (40), T lymphocytes will respond to the pathogen, differentiation of $\mathrm{T}$ helper (Th) to Th 1 cells and this will generate GM-CSF and other cytokines that activate and stimulate the production of $\mathrm{CD} 4+, \mathrm{CD} 8+$, and monocytes and releases a huge amount of IL6, which facilitate more lung inflammatory cells infiltration and monocytes that migrate to the lung and developed into macrophage or monocytederived dendritic cells. These cells will produce a high level of IL6 and GM-SCF and increased plasma concentrations of pro-inflammation cytokines as interleukins IL2, IL7, and IL10, monocyte chemoattractant protein1 (MCP1), interferon-inducible protein 10 (IP10), macrophage inflammatory protein 1 alpha (MIP1A) and tumor necrosis factor $\alpha$ (TNF $\alpha$ ). Accumulation of these chemicals results in an inflammatory storm due to cytokine/chemokine dysregulated responses after higher virus titers appear and lead to lung immunopathy (43). Chen et al. (44) and Diao et al. (45) reported that CD4+T, CD8+ T cells, and B cells were reduced in SARS-CoV-2. However, both Zheng et al. (46) and Zheng et al. (47) showed that blood peripheral leukocytes were normal. levels and no differences in the plasma concentration levels of IL-6 and TNF-a and there were differentially expressed functional molecules as IFNgamma and TNF- $\alpha$ in CD4+ T cells lower in the severe group, while perforins and granzyme $\mathrm{B}$ levels in CD8+T cells were higher in the severe group than in the mild group. Similar to this response was noticed in some chronic infections that will damage the function of CD4+ T cells and produced excessive activation and exhaustion of CD8+ T cells. In severe patients, exhaustion of CD8+ T cells and NK cells reduce the cellular immune response to SARS-CoV-2 and impair antiviral immunity at an early stage (46-47).

\section{Conclusions}

COVID -19 is a disease of global attention. The mortality due to COVID -19 may be explained by the early loss of control on the innate immune system. The key to protecting from infection with COVID -19 may be through an early controlling response of both innate and adaptive immunity. The main factor in the prevalence and death rate was patient ages. Race for vaccine production to control of Covide-19 pandemic that began, but there are experiments until now for the treatment of infection by Hydroxychloroquine /azithromycin or Lipopolysaccharide or using passive immunity.

\section{Acknowledgments}

The Authors are very grateful to head of the Department of Microbiology and College of Veterinary Medicine Deanship at the University of Mosul for their efforts and supporting us to finish the current review.

\section{Conflict of interest}

The authors declare that there is no conflict of interest.

\section{References}

1. https://www.who.int/emergencies/diseases/novel-coronavirus-2019

2. Iraq ministry of public health https://moh.gov.iq/index.php?name= News \&file $=$ article $\&$ sid $=14319$

3. Jiang F, Deng L, Zhang L, Cai Y, Cheung CW, Xia Z. Review of the clinical. characteristics of coronavirus disease 2019 (COVID-19). J Gen Intern Med. 2020;26.:1-5. Doi: 10.1007/s11606-020-05762-w.

4. Deng CX. The global. battle against SARS-CoV-2 and COVID-19. Int J Biol Sci. 2020;16(10):1676-1677. Doi:10.7150/ijbs.45587.

5. Murphy AF, Gibbs EPJ, Horzinek CM, Studdert JM.Vet Virol. $3^{\text {rd }}$ ed. San Diego: Academic Press Elsevier; 1999. 495-509,127-161 p. https://www.elsevier.com/books/veterinary-virology/murphy/978-012-511340-3

6. Carter BJ, Saunders AV. Virology principle and application. $2^{\text {nd }}$ ed. England: John Wiley; 2007. 103-114 p. https://www.wiley.com/enus/Virology\%3A+Principles+and+Applications \%2C+2nd+Edition-p9781119991427

7. MacLachlan JN, Dubovi JE. Fenner's veterinary virology. 4th ed. London: Academic Press; 2017. 75-100,393-419 p. Doi:10.1016/C2013-0-06921-6>

8. Ashour HM, Elkhatib WF, Rahman M, Elshabrawy HA. Insights into the recent 2019 novel coronavirus (SARS-CoV-2) in light of past human coronavirus outbreaks. Pathogens. 2020;9(3):186. Doi:10.3390/pathogens9030186.

9. Drosten C, Günther S, Preiser W, Van der WS, Brodt H, Becker S, Rabenau H, Panning M, Kolesnikova L, Fouchier RA M, Berger A, Burguière A, Cinatl J, Eickmann M, Escriou N, Müller GK, Kramme 
S, Manuguerra J, Rickerts V, Stürmer M, Vieth S, Klenk H, Osterhaus $\mathrm{AD}$, Schmitz H, Doerr WH. Identification of a novel coronavirus in patients with severe acute respiratory syndrome. $\mathrm{N}$ Engl $\mathrm{J}$ Med. 2003;348(20):1967-1976. Doi:10.1056/NEJMoa030747

10. Zaki AM, Van Boheemen S, Bestebroer TM, Osterhaus AD, Fouchier RA. Isolation of a novel coronavirus from a man with pneumonia in Saudi Arabia. N Engl J Med. 2012;367(19):1814-1820. Doi:10.1056/NEJMoa1211721.

11. Lorusso A, Calistri P, Petrini A, Savini G, Decaro N. Novel coronavirus (SARS-CoV-2) epidemic: A veterinary perspective. Vet Ital. 2020;12:1-6. Doi:10.12834/VetIt.2173.11599.1.

12. Shereen MA, Khan S, Kazmi A, Bashir N, Siddique R. COVID-19 infection: Origin, transmission, and characteristics of human $\begin{array}{llll}\text { coronaviruses. J Adv 2020;15.:91-98. } & \text { Res. }\end{array}$ Doi:10.1016/j.jare.2020.03.005.

13. Han Y, Yang H. The transmission and diagnosis of 2019 novel coronavirus infection disease (COVID-19): A Chinese perspective. J Med Virol. 2020;92(6):634-644. Doi:10.1002/jmv.25749.

14. Van Doremalen N, Bushmaker T, Morris HD, Holbrook GM, Gamble A, Williamson NB, Tamin A, Harcourt LJ, Thornburg JN, Gerber IS, Lloyd-Smith OJ, De Wit E, Munster JV. Aerosol and surface stability of SARS-CoV-2 as compared with SARS-CoV-1. N Engl J Med. 2020; 382 (16):1564-1567. Doi:10.1056/NEJMc2004973.

15. Lo IL, Lio CF, Cheong HH, Lei CI, Cheong TH, Zhong X, Tian Y, Sin NN. Evaluation of SARS-CoV-2 RNA shedding in clinical. specimens and clinical. characteristics of 10 patients with COVID-19 in Macau. Int J Biol Sci. 2020;16(10):1698-707. Doi:10.7150/ijbs.45357.

16. Lu C, Liu X, Jia Z. 2019-nCoV transmission through the ocular surface must not be ignored. Lancet. 2020;395(10224): e39. Doi:10.1016/S0140-6736(20)30313-5.

17. Peng X, Xu X, Li Y. Cheng L, Zhou X, Ren B. Transmission routes of 2019-nCoV and controls in dental. practice. Int J Oral. Sci. 2020;12(9):1-5. Doi:10.1038/s41368-020-0075-9.

18. Bai Y, Yao L, Wei T, Tian F, Jin D, Chen L, Wang M. Presumed asymptomatic carrier transmission of COVID-19. JAMA. 2020; 323(14):1406-1407. Doi:10.1001/jama.2020.2565.

19. Al-Tawfiq AJ. Asymptomatic coronavirus infection: MERS-CoV and SARS-CoV-2 (COVID-19). Travel Med Infect Dis. 2020;27: 101608:1-2. Doi:10.1016/j.tmaid.2020.101608.

20. Carrasco-Hernandez R, Jácome R, López Vidal. Y, Ponce de León S. Are RNA viruses candidate agents for the next global. pandemic? A review. ILAR J. 2017;58(3):343-358. Doi:10.1093/ilar/ilx026.

21. Lu R, Zhao X, Li J, et al. Genomic characterisation and epidemiology of 2019 novel coronavirus: implications for virus origins and receptor binding. Lancet. 2020; 395(10224):565-574. doi:10.1016/S01406736(20)30251-8.

22. Zhang C, Zheng W, Huang X, Bell W. E., Zhou X, Zhang Y. Protein Structure and Sequence Reanalysis of 2019-nCoV Genome Refutes Snakes as Its Intermediate Host and the Unique Similarity between Its Spike Protein Insertions and HIV-1. J Proteome Res. 2020;19: 1351-1360. Doi:10.1021/acs.jproteome.0c00129.

23. Rabi AF, Al. Zoubi SM, Kasasbeh AG, Salameh MD, Al-Nasser DA. SARS-CoV-2 and coronavirus disease 2019: What we know so far. Pathogens. 2020;9(3):231. Doi:10.3390/pathogens9030231.

24. Tang X, Wu C, Li X, Song Y, Yao X, Wu X, Duan Y, Zhang H, Wang Y, Qian Z, Cui J. On the origin and continuing evolution of SARSCoV-2. Nat Sci Rev. 2020;nwaa036:1-26. Doi:10.1093/nsr/nwaa036.

25. Coutard B, Valle C, de Lamballerie X, Canard B, Seidah NG, Decroly E. The spike glycoprotein of the new coronavirus 2019- ,nCoV contains a furin-like cleavage site absent in $\mathrm{CoV}$ of the same clade. Antiviral. Res. 2020;1(176):104742. Doi:10.1016/j.antiviral.2020.104742.

26. Wrapp D, Wang N, Corbett KS.,Goldsmith JA, Hsieh CL, Abiona O, Graham BS, McLellan JS. Cryo-EM structure of the 2019-nCoV spike in the prefusion conformation. Sci. 2020;367:1260-1263. Doi:10.1126/science.abb250.
27. Rothe C, Schunk M, Sothmann P, Bretzel G, Froeschl G, Wallrauch C, Zimmer T, Thiel, Janke C, Guggemos W, Seilmaier M, Drosten C, Vollmar P, Zwirglmaier K, Zange S, Wölfel R, Hoelscher M. Transmission of 2019-nCoV infection from an asymptomatic contact in Germany. N Engl J Med. 2020;382(10):970-971. Doi:10.1056/NEJMc2001468.

28. Prompetchara E, Ketloy C, Palaga T. Immune responses in COVID-19 and potential. vaccines: Lessons learned from SARS and MERS epidemic. Asian Pac J Allergy Immunol. 2020;38(1):1-9. Doi:10.12932/AP-200220-0772.

29. Huang C, Wang Y, Li X, Ren L, Zhao J, Hu Y, Zhang L, Fan G, Xu J, Gu X, Cheng Z, Yu T, Xia J, Wei Y, Wu W, Xie X, Yin W, Li H, Liu M, Xiao Y, Gao H, Guo L, Xie J, Wang G, Jiang R, Gao Z, Jin Q, Wang J, Cao B. Clinical. features of patients infected with 2019 novel coronavirus in Wuhan, China. Lancet. 2020;395(10223):497-506. Doi:10.1016/S0140-6736(20)30183-5.

30. Kikkert M. Innate immune evasion by human respiratory RNA viruses. J Innate Immun. 2020;12(1):4-20. Doi:10.1159/000503030.

31. Li G, Fan Y, Lai Y, Han T, Li Z, Zhou P, Pan P, Wang W, Hu D, Liu $\mathrm{X}$, Zhang Q. Coronavirus infections and immune responses. J Med Virol. 2020;92(4):424-32. Doi:10.1016/j.tmaid.2020.101575.

32. Li X, Geng M, Peng Y, Meng L, Lu S. Molecular immune pathogenesis and diagnosis of COVID-19. J Pharmaceut Anal. 2020;5:1-7. Doi:10.1016/j.jpha.2020.03.001.

33. Xu Z, Shi L, Wang Y, Zhang J, Huang L, Zhang C, Liu S, Zhao P, Liu H, Zhu L, Tai Y. Pathological. findings of COVID-19 associated with acute respiratory distress syndrome. Lancet Res Med. 2020; 8(4):420422. Doi:10.1016/S2213-2600(20)30076-X.

34. Nezhad SF, Mosaddeghi P, Negahdaripour M, Dehghani Z, Farahmandnejad M, Moghadami M, Nezafat N, Masoompour S M. Therapeutic approaches for COVID-19 Based on the dynamics of interferon-mediated immune responses. Preprints. 2020; 2020030206. Doi:10.20944/preprints202003.0206.v1.

35. Bao L, Deng W, Gao H, Xiao C, Liu J, Xue J, Lv Q, Liu J, Yu P, Xu Y, Qi F. Reinfection could not occur in SARS-CoV-2 infected rhesus macaques. bioRxiv. 2020;1. Doi:10.1101/2020.03.13.990226,2020.

36. Dong C, Ni L, Fang Ye, Meng-Li C, Yu F, Yong-Qiang D, Hui Z, Peng W, G, Xiaoli L, Lin, Pengzhi W, Peng L, Han G, Xinquan W, ChengFeng Q. Characterization of anti-viral. immunity in recovered individuals infected by SARS-CoV-2. medRxiv. 2020;17. Doi:10.1101/2020.03.17.20036640.

37. Tan L, Wang Q, Zhang D, Ding J, Huang Q, Tang YQ, Wang Q, Miao H. Lymphopenia predicts disease severity of COVID-19: a descriptive and predictive study. Signal. Transduct Target Ther. 2020; 5(33):1-3. Doi:10.1038/s41392-020-0148-4.

38. Zeng Q, Li YZ, Huang G, Wu W, Dong SY, Xu Y. Mortality of COVID-19 is associated with cellular immune function compared to immune function in Chinesese han population. medRxiv. 2020;1. Doi:10.1101/2020.03.08.20031229.

39. Chen X, Ling J, Mo P, Zhang Y, Jiang Q, Ma Z, Cao Q, Hu W, Zou S, Chen L, Yao L. Restoration of leukomonocyte counts is associated with viral. clearance in COVID-19 hospitalized patients. medRxiv. 2020;1. Doi:10.1101/2020.03.03.20030437.

40. Lin L, Lu L, Cao W, Li T. Hypothesis for potential. pathogenesis of SARS-CoV-2 infection--a review of immune changes in patients with viral. pneumonia. Emerg Microbes Infect. 2020; 9(1):727-732. Doi: $10.1080 / 22221751.2020 .1746199$.

41. Xie J, Fan HW, Li TS, Qiu ZF, Han Y. Dynamic changes of T lymphocyte subsets in the long-term follow-up of severe acute respiratory syndrome patients. Act Acad Med Sci. 2006;28(2):253-255. http://www.actacams.com/EN/Y2006/V28/I2/253 https://pubmed.ncbi.nlm.nih.gov/16733915

42. Wang D, Hu B, Hu C, Clinical. Characteristics of 138 hospitalized patients with 2019 novel coronavirus-infected pneumonia in Wuhan, China. JAMA. 2020;323(11):1061-1069. Doi:10.1001/jama.2020.1585. 
43. Zhou Y, Fu B, Zheng X, Wang D, Zhao C, Sun R, Tian Z, Xu X, Wei $\mathrm{H}$. Pathogenic T cells and inflammatory monocytes incite inflammatory storm in severe COVID-19 patients. Nat Sci Rev. 2020; 13.nwaa041:115. Doi:10.1093/nsr/nwaa041.

44. Chen C, Qi F, Shi K, Li Y, Li J, Chen Y, Pan J, Zhou T, Lin X, Zhang J, Luo Y, Li X, Xia J. Thalidomide combined with low-dose glucocorticoid in the treatment of COVID-19 pneumonia. Preprints allergology. 2020;2020020395. https://www.preprints.org/ manuscript/202002.0395/v1

45. Diao B, Wang C, Tan Y, Chen X, Liu Y, Ning L, Chen L, Li M, Liu Y, Wang G, Yuan Z. Reduction and functional. exhaustion of T cells in patients with coronavirus disease 2019 (COVID-19). medRxiv. 2020;1. Doi:10.1101/2020.02.18.20024364.

46. Zheng H, Zhang M, Yang C, Zhang N, Wang X, Yang X, Dong X, Zheng Y. Elevated exhaustion levels and reduced functional. diversity of $\mathrm{T}$ cells in peripheral. blood may predict severe progression in COVID-19 patients. Cell Mol Immunol. 2020;17:1-3 Doi:10.1038/s41423-020-0401-3.

47. Zheng M, Gao Y, Wang G, Song G, Liu S, Sun D, Xu Y, Tian Z. Functional. exhaustion of antiviral. lymphocytes in COVID-19 patients. Cell Mol Immunol. 2020;19:1-3. Doi:10.1038/s41423-0200402-2. 